\title{
Notas para una Historia de la Higiene tomadas de la Biblia
}

\author{
Walter Ledermann
}

\section{Notes for a History of Hygiene taken from the Bible}

Reading once more the Gospels, we found a discussion between Jesus and the Pharisee about the hand washing, this golden rule of medicine, and then, with the help of Thomas Mann, we began a search for other notes on hygiene in the Bible. For the return from Egypt to the Promised Land, Moses established several rules for his people, some of them disguised as religious principles, concerning elimination of excreta, healthy and poisonous foods, isolation in case of contagious diseases (leprosy, gonorrhea), decontamination of clothes and houses, and many others that now seem to us ahead his time.

Key words: Hygiene, Bible, Thomas Mann, leprosy, gonorrhea.

Palabras clave: Higiene, Biblia, Thomas Mann, lepra, gonorrea.
Centro de Estudios Humanistas Julio Prado. Santiago de Chile.

Recibido: 26 de junio de 2016

Correspondencia a: Walter Ledermann Dehnhardt revinf@sochinf.cl
$\mathrm{C}$ ualquiera que sea la fe que se profese, o ninguna, conviene releer de cuando en cuando los Evangelios, por cuanto su contenido es fuente, al parecer inagotable, de hallazgos que incitan a la meditación, generando nuevas ideas y aperturas mentales. Consecuente con este pensamiento, nuestra última incursión en el Nuevo Testamento ha tropezado con unos versículos de Mateo y de Marcos que nos han sumido, desde el punto de vista infectológico, en honda perplejidad.

Unos fariseos y maestros de la Ley que habían venido de Jerusalén se acercaron a Jesús -dice Mateo- y le dijeron: ¿Por qué tus discípulos no respetan la tradición? No se lavan las manos antes de comer ${ }^{1}$.

Jesús tiene tres respuestas distintas:

- A los acusadores responde echándoles en cara una falta mayor: no respetar la tradición de honrar padre y madre.

- A la gente común, con esta sentencia: lo que entra por la boca no hace impura a la persona, pero sí mancha a la persona lo que sale de su boca.

- A los discípulos amplía dicha explicación: ¿No comprenden que todo lo que entra por la boca va al estómago y después termina en el basural? En cambio, lo que sale de la boca procede del corazón, y eso es lo que hace impura a una persona. Del corazón proceden los malos deseos, asesinatos, adulterio, inmoralidad sexual, robos, mentiras, chismes. Estas son las cosas que hacen impuro al hombre, pero el comer sin lavarse las manos no hace impuro al hombre.

La versión de $\operatorname{Marcos}^{2}$ para este hecho es muy similar, de modo que la omitimos, para ir a lo medular del incidente. Si consideramos a Jesús sólo un profeta, podemos interpretar su respuesta como una reacción al continuo hostigamiento que sufría por parte de los fariseos, haciéndoles ver que lo recriminaban por hechos de poca importancia, faltando ellos al cumplimiento de leyes morales más importantes. Su explicación, en cambio, nos resulta difícil de entender si lo consideramos el Hijo de Dios, omnisciente, salvo que los infectólogos estemos equivocados y el lavado de manos, ritual que los médicos adoramos cual dogma indiscutible, sea innecesario. Y, como estamos entrando en terreno resbaladizo y podemos ofender la fe, lo abandonamos para pasar a los hechos puramente históricos, con la tranquilidad que nos da saber que la esencia del cristianismo es la bondad y el amor al prójimo, de modo que nos perdonarán si hemos faltado.

La norma citada por los fariseos como parte de la tradición era una de las tantas medidas higiénicas instauradas por Moisés. En una curiosísima y poco conocida obra de

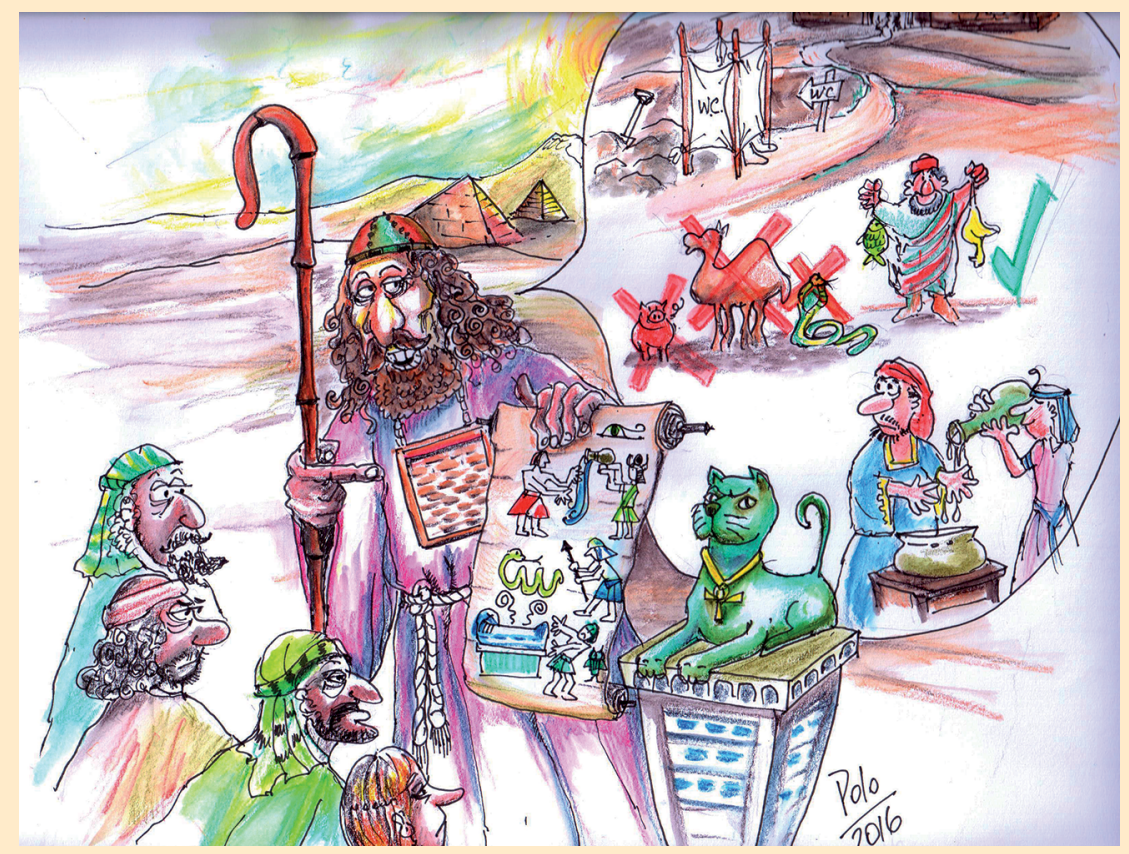


Thomas Mann, el "Mago" imagina qué habría ocurrido si Moisés hubiera sido egipcio, haciéndolo nacer de un momento de lujuria entre la hija del faraón y un obrero judío, asesinado luego, cuando los sicarios de la princesa aplicaron literalmente su orden de "hacerlo desaparecer", siguiendo así la triste suerte del zángano, mientras que la abeja reina-llamemos de este modo a la pecadora-dio a luz con el tiempo a un robusto niño, inventando la fábula del canastito en el agua para salvar su honor. Criado y educado como príncipe, Moisés tomó lo mejor de ambas etnias, hebrea y egipcia, y así como adoptó la superior ética judía, también hizo suyos los avances médicos de la nación que lo cobijaba, y de esta manera las normas higiénicas que adoptó el pueblo elegido de regreso a casa, estimándolas dictadas a su guía directamente por Jehová, derivaban en verdad de la excelente educación de aquél, que le había permitido conocer y entender los principios básicos de la higiene desarrollada por la nación egipcia a lo largo de siglos.

Thomas Mann reseña todas estas prácticas higiénicas, extrayéndolas del Antiguo Testamento y dándoles una explicación racional y no divina, al igual que hace con las siete plagas; no interesándonos por ahora éstas, veamos aquéllas, aprovechando, como flojos que somos, la búsqueda que hizo nuestro autor favorito.

Según Mann, comienza Moisés con la prohibición de defecar dentro de las murallas de la ciudad, porque allí moraba Jehová, pero esta norma aparece recién en el "Segundo discurso de Moisés" del Deuteronomio ${ }^{4}$, donde se refiere a la limpieza cuando se está en guerra: Cuando salgas de campaña contra enemigos, guárdate de toda cosa indecente. Tendrás fuera del campamento un lugar donde podrás salir. Tendrás también en tu equipo una estaca, con la cual harás un hoyo cuando estés sentado fuera, y antes de volver cubrirás tus excrementos. Moisés ponía en boca de Jehová esta normativa, quizás porque verdaderamente escuchaba su voz, quizás para darle mayor valor y ascendiente sobre las masas, pero la razón esgrimida - la ofensa a la divinidad - esconde la finalidad higiénica: la noción que Moisés, ya fuera por su propia observación o por las enseñanzas recibidas de médicos egipcios, tenía sobre la transmisión de infecciones a través de las deposiciones. Esta sabia costumbre la han conservado los gatos, que en Egipto eran muy estimados, tanto que matar un gato merecía pena de muerte y había, incluso, una diosa gatuna, de nombre Bastet.

¿Se asombra el lector? El gato hace su hoyito, defeca en él y luego lo cubre con tierra, ayudándose del olfato para comprobar si ha quedado bien cubierto; ahora bien, si es gato exquisito y educado, no realiza esta maniobra en su casa, sino en el jardín del vecino. El perro, animal estúpido, conserva un rudimento de esta costumbre, pero deposita su mugre en cualquier parte, incluso en el pavimento, y luego hace ademán de echar tierra encima con sus patas traseras.
¿Hablaba Jehová a Moisés? Indudablemente, pero no a la oreja. Muchos santos también han hablado con Dios, a quien concebían como una criatura antropomorfa, en la incapacidad de imaginar una criatura superior, perfecta, inmaterial, espiritual, perenne; pero si usted, amable lector, es creyente, coincidirá con nosotros que Dios no habla al oído sino al corazón del hombre... y sin necesidad de palabras.

Sigamos con las recomendaciones que Mann pone en boca de su héroe, como la de bañarse en agua corriente para preservar la salud, pues si prefieren andar sucios, son unos imbéciles, que se verán acosados por ictericias, verrugas y forúnculos de Egipto. Atina el líder en que la higiene es útil en la prevención de la hepatitis $\mathrm{A}$, pero nos sorprende al considerar las estafilococcias como propias del pueblo egipcio. Y agrega que cuando un hombre... -o mujer-(que si Moisés tenía cuidado con esta cuestión del género, hoy tan de moda, nosotros no haremos menos) tenga llagas o erupciones malignas, tumores, heridas llagadas o con sangre, se considerará impuro y no será tolerado en el campamento, siendo conducido a un lugar aislado.

Estas medidas demuestran que habían observado -los judíos y/o los egipcios- la existencia de factores comunes en el contagio de ciertas patologías, puesto que desinfectaban objetos y vestidos que habían estado en contacto con los enfermos, incluso a veces los quemaban, y tenían normas de aislamiento y de cuarentena. A veces exageraban y erraban, como en el caso de la mujer menstruante, a quien estimaban impura, contaminando por este hecho fisiológico vestidos, muebles, sillas de montar y vasijas, objetos que debían lavarse con agua; más no exageraban ni erraban al aplicar normas más severas en el caso del varón con flujo, es decir, con gonorrea ${ }^{5}$.

Prosigue Moisés con una serie de recomendaciones sobre la alimentación, estableciendo qué animales pueden comerse y cuáles no, "porque debéis comer unas cosas y otras desecharlas, y sentir placer por unas y repugnancia por otras". De carnes rojas estaban permitidas las de rumiantes con pezuña hendida, lo que dejaba fuera la carne equina; del pescado, "todo cuanto en el agua tenga aletas y escamas, no así lo que se desliza en el agua, como las salamandras"; prohibiendo también "cualquier alimaña que se desliza por el suelo o se arrastra sobre su vientre".

Yendo a las fuentes bíblicas, las recomendaciones que Mann cita eran harto más extensas y detalladas. "Todo animal biungulado de pezuña hendida que rumie, ese podrás comer", establece Moisés, excluyendo como impuras, por faltarle uno de estos dos requisitos, las carnes de camello, conejo, liebre y cerdo ${ }^{6}$. La prohibición de comer carne de camello, animal utilísimo para el transporte y la carga, parece tener una finalidad económica, práctica, y no higiénica: que sepamos, este animal no trasmite ninguna plaga en especial, y tampoco el caballo, que cumple las mismas funciones y es igualmente prohibido 
en otro versículo. En cuanto a no comer conejo ni liebre, la prohibición nos parece sin mucho sentido.

"De los animales que viven en las aguas, a cuantos teniendo aletas y escamas se encuentren en los mares y en los ríos, a éstos podrás comer, pero serán cosa abominable los que carecen de aletas y escamas" (nada se dice de la salamandra). De entre las aves, "abominables serán, no se comerán y os serán detestables: águila, quebrantahuesos, águila marina, buitre, halcones, cuervo, avestruz, lechuza, gaviota, gavilanes, búho, somormujo, ibis, cisne, pelícano, calamón, cigüeña, garzas, abubilla y murciélago. Son abominables todos los insectos alados de cuatro patas, salvo los que saltan, como la langosta, solam, hargol y hagab". Según una nota al pie en la Vulgata Latina, estas tres últimas eran distintas especies de langosta ( $a r b e b$, en hebreo), que en Palestina entonces eran comestibles y lo siguen siendo en muchos pueblos meridionales y orientales ${ }^{7}$. Otra razón puramente práctica, considerando que en las plagas constituían un importante y gratuito aporte proteico: se podían comer fritas y en escabeche, y más de algún célebre chef las ocupa hoy en día, cobrando por ellas precios escandalosos a los esnob.

Tocante a los reptiles, todos eran condenados como "abominables".

Hay otras prohibiciones fundadas en razones religiosas. Jehová habló a Moisés, dice el Levítico ${ }^{8}$ y le ordenó: "Habla a los hijos de Israel y diles: No comeréis sebo de buey, ni de oveja ni de cabra. El sebo de animal muerto o destrozado podrá servir para cualquier uso, pero en modo alguno lo comeréis. Porque todo aquel que coma sebo de animal que suele quemarse en honor de Yahvé, será extirpado de entre su pueblo. Tampoco comerás sangre, ni de ave ni de cuadrúpedo".

Con una raíz sanitaria, encontramos las disposiciones sobre los cadáveres, que declaran "inmundo" al que los toque, al igual que los objetos contaminados por ellos, como ropa, recipientes, incluyendo el horno y el fogón que "serán derribados". Pero, como curiosidad y sin duda con fines prácticos, las fuentes y las cisternas donde se recogen las aguas quedarán limpias, al igual que la semilla por sembrar, con una salvedad: "mas, si cayere algo de esos cuerpos muertos sobre la semilla mojada, la tendrás por inmunda”, dice Yahvé. ¿Por estimar que la humedad favorecería el desarrollo microbiano, es decir, la podredumbre, que la sequedad evitaría?

Para terminar con las impurezas, recordemos que también se estimaba impura, al igual que la menstruante, a la parturienta, con una odiosa salvedad: si había parido varón, se requerían siete días de purificación, igual que para la menstruación, pero si había parido mujer, se necesitaba el doble, es decir, dos semanas. El menosprecio del género femenino empezaba al nacer la criatura.

Las enfermedades a prevenir con todas estas normas pueden haber sido algunas de las infecciosas clásicas, que aparecen con frecuencia en el Libro, como la tuberculosis, la lepra, la viruela y la sarna. En ellas el elemento sagrado estaba siempre presente, considerándose la enfermedad como un castigo divino que, por lo mismo, el médico sólo podía curar con la ayuda de Dios. Quizás si donde mejor se aprecia este concepto punitivo es en el Libro de Job ${ }^{10}$, que de paso describe lesiones interpretadas a menudo como diviesos o furúnculos, elementos infecciosos que hoy sabemos causados por la bacteria Staphylococcus aureus. Job, cuyo nombre significa "el perseguido" en hebreo y "el arrepentido" en árabe, habría vivido en Uz, en los tiempos de Abraham, por ahí por el siglo IV a. C., siendo un hombre próspero, dueño de extensas tierras y grandes ganados y padre de diez hijos, para terminar injustamente castigado y arruinado por Jehová.

Al escribir la historia del Staphylococcus aureus ${ }^{11}$ contábamos que en 1817 el pintor, poeta, místico y filósofo inglés William Blake (1757-1827) había efectuado una serie de grabados para ilustrar el bíblico "Libro de Job", en uno de los cuales, el llamado Job afflicted with sore boils from the sole of his foot to the crown of his head, se ha encontrado una alusión al Staphylococcus aureus, pues boils suele y puede traducirse como absceso o divieso, esto es, furúnculo. Pero, como Job está dibujado con la cabeza reclinada hacia atrás, pareciera en posición de opistótonos, propia del tétanos o de una meningitis avanzada, Verghese y Gallemore ${ }^{12}$ piensan que Job hubiera podido ser víctima de una meningococcemia.

Hace rato dejamos ya a Mann, luego de piratearlo y hemos entrado derechamente en el Antiguo Testamento, para encontrarnos con un Jehová que, a semejanza de los dioses griegos, comparte las humanas pasiones, comportándose a veces como un Zeus iracundo y otras como un Ares marcial. El Libro de Job es un trágico ejemplo de las actitudes a veces inconcebibles -o incomprensibles- de Jehová, quien no trepida en agobiar con miserias a su siervo para obtener un pequeño triunfo sobre Satanás. Como el demonio sostuviera que Job glorificaba a Dios porque recibía sólo bienes del cielo, y que cambiaría radicalmente de actitud si en vez de bienes recibiera males, Jehová permite que mueran no sólo los animales de su siervo, sino también todos sus hijos, y como el buen hombre continúa alabándolo, autoriza ahora que caiga sobre éste un terrible peste: "Satanás hirió a Job con una úlcera maligna, de la planta de los pies hasta la coronilla de la cabeza". De este versículo deriva la clásica expresión "estoy hasta la coronilla".

Job, postrado, se lamenta, describiendo su condición con estas palabras: "Mi mujer tiene asco de mi hálito y para los hijos de mis entrañas no soy más que hediondez... ennegrecida se me cae la piel y mis huesos se consumen por la fiebre". Ahora bien, como a estas alturas sus hijos ya estaban muertos, un comentarista en nuestro ejemplar de la Biblia, en letra chica y al pie de página, explica que se 
refiere a sus hermanos... ¡Caramba! ¿Los hermanos de sus entrañas? Pero, en relación a la patología infecciosa que nos interesa, vemos que tenía úlceras, que la piel se le caía y la fiebre lo consumía, todo lo cual pudiera bien corresponder a una infección estafilocóccica como el síndrome de la piel escaldada, pero de diviesos nada se dice, siendo lo más probable que Blake los haya entrevisto en algunas de sus visiones místicas, a las cuales era muy propenso.

Este famoso William Blake era un inglés, nacido el 28 de noviembre de 1757 y fallecido a los 69 años, el 12 de agosto de 1827, quien no sólo ilustró la Biblia, atreviéndose también con Dante y su Divina Comedia y Milton y su Paraíso perdido, fue un artista completo, pues además de grabador ejerció como pintor y poeta, siendo su obra principal el "Matrimonio del cielo y el infierno". No muy cotizado en vida, hoy está quizás sobrevalorado, como suele ocurrir.

Visiones tuvo este artista desde niño: a los nueve años vio un árbol lleno de ángeles, que lanzaban en las ramas destellos como estrellas, visión que casi le mereció una paliza de su incrédulo padre ${ }^{13}$. Más tarde vería ángeles caminando entre unos segadores, y en otra ocasión la cabeza de Dios asomada a la ventana, visión que lo hizo lanzar alaridos ${ }^{14}$. Entonces, ver estafilococos infectando la piel de Job sería para este gran visionario un moco de pavo.

Todos los estudiosos de las enfermedades infecciosas y de la medicina en general han terminado por aceptar la teoría de los diviesos, a tal punto que se ha denominado síndrome de Job a una enfermedad inmunitaria descrita en 1966, donde Staphylococcus aureus es la bacteria beneficiada, ensañándose en los pobre enfermos, todos unos nuevos Jobs. Este síndrome, es decir, conjunto de signos y síntomas, se ha llamado también de hiper IgE, de Job Buckley, de Buckley y de hiper inmuno globulinemia E estafilocóccica (HIE), y se debe a un defecto genético, radicado en el cromosoma 4q21, que afecta a la inmunidad y favorece las infecciones no sólo por Staphylococcus aureus, participando también de la agresión Streptococcus pneumoniae, Haemophilus influenzae, el hongo Candida albicans y el virus Herpes simplex ${ }^{15}$.

Pero más información sobre la medicina judía que en el libro de Job, encontramos en Eclesiástico": "Honra al médico, porque lo necesitas; porque el Altísimo es quien lo ha hecho. Porque de Dios viene toda medicina y el médico será remunerado por el rey. El Altísimo creó de la tierra los medicamentos (¿serán las hierbas o los antibióticos?) y el hombre prudente no los desecha. La virtud de los medicamentos pertenece al conocimiento de los hombres; el Señor se la ha descubierto para que le glorifique por sus maravillas. Con ellas cura y mitiga los dolores; el boticario hace composiciones suaves y forma ungüentos saludables. Hay un tiempo en que caerás en manos de los médicos y ellos rogarán al Señor para que les conceda lograr alivio y salud por su tratamiento".
Y es muy moderna, dadas la situación y la carestía de la medicina actual, la terrible advertencia: "Caerá en manos del médico el que peca en presencia de su Creador".

Se ha querido encontrar una alusión a la sífilis en la Biblia a propósito de plaga que afligió al pueblo de Moab, por haberse entregado las hijas de este pueblo a la fornicación con los israelitas que huían de Egipto ${ }^{17}$, en circunstancias que esta enfermedad apareció en coincidencia con el descubrimiento de América, apresurándose los europeos en declararla originaria del nuevo continente, aunque numerosos hallazgos demuestran lo contrario. En Números 25 se lee que la plaga mató 24.000 personas: como no hay descripción alguna de los síntomas y signos de dicha enfermedad, y como la plaga fue fulminante, matando a todos en brevísimo tiempo, no existe el menor asidero para atribuirla al Treponema pallidum.

La enfermedad de transmisión sexual que sí se relata es la gonorrea, llamada flujo seminal, considerada una putrefacción del semen, al respecto de la cual Moisés dictó algunas leyes, que ordenaban la purificación rigurosa de las ropas y objetos del enfermo, así como su aislamiento hasta siete días después de acabados los síntomas.

De vuelta a los Evangelios, donde se narran los milagros de Cristo, una rápida revisión nos muestra, desde el punto de vista infeccioso, sólo la cura de varios leprosos, que son minoría entre las curaciones de varias otras patologías: ceguera, posesión, epilepsia, parálisis, mano seca, mudez... y muerte (resurrección de Lázaro, milagro que más tarde repetiría San Pablo con otro fallecido).

Haciendo un balance, la enfermedad más mencionada en el libro sagrado es la lepra, pero hay que ir con mucho cuidado al interpretar el texto, pues bajo el término lepra se cobijan males muy distintos, situación agravada por traducciones equívocas del hebreo antiguo. En la Biblia se le asigna un fuerte componente espiritual, ligado al concepto de castigo divino, de manera que el enfermo, castigado por Jehová, era apartado y discriminado, como se lee en el Levítico ${ }^{18}$ : "Cuando el hombre tuviere en la piel de su cuerpo hinchazón, o erupción, o mancha blanca, y hubiere en la piel de su cuerpo como llaga de lepra, será traído a Aaron el sacerdote. Y el sacerdote mirará la llaga en la piel del cuerpo; si el pelo en la llaga se ha vuelto blanco, y pareciere la llaga más profunda que la piel de la carne, llaga de lepra es; y el sacerdote le reconocerá y le declarará inmundo". Si la llaga no era más profunda que la piel, el enfermo debía ser examinado cada siete días, hasta descartar la infección o sentenciarla, en cuyo triste caso "el afectado por la lepra llevará sus vestidos rasgados, dejará descubierta su cabeza, se tapará la boca y caminará gritando ;impuro, impuro! y habitará solo: fuera del campamento será su morada"19.

Los signos y síntomas mencionados como propios de la lepra son muy variados y se salen del cuadro: erupción, diviesos, manchas, inmundicia, cicatrices... Las únicas 
observaciones valiosas para nosotros y que confirman la existencia de lepra son la evolución crónica, progresiva, y la necesidad de aislamiento, demostrativa de la existencia del concepto de contagio, que obligaba a segregar a los enfermos, como se expresa en Números ${ }^{20}$ : “Jehová habló a Moisés, diciendo: Manda a los hijos de Israel que echen del campamento a todo leproso, y a todos los que parecen flujo de semen (gonorrea)". En el mismo libro se insiste en la blancura como signo de lepra: "Y la nube se apartó del tabernáculo, y he aqui que María estaba leprosa como la nieve" 21 .

Lo más destacable en relación a esta antigua enfermedad infecciosa, sobre la cual se pueden encontrar varias otras referencias en la Biblia, es la existencia de normas de aislamiento para los enfermos, claras y precisas, que anteceden en siglos a la cuarentena ideada para los navíos con apestados a fines de la Edad Media.

Como curiosidad está la creencia en la posible propagación de la enfermedad a las ropas y a las casas, examinando el sacerdote, siempre de siete en siete días, si la mancha de lepra en el vestido se extendía, haciéndola primero lavar, para continuar cortando el pedazo infectado $y$, eventualmente, terminar por quemarla ${ }^{22}$; en tanto que para las manchas en las paredes -verdes, rojizas, cavitadas-la sucesión de tentativas de erradicación consistían en lavar, revocar, arrancar piedras, hasta derribarlas y arrojar los escombros inmundos fuera del poblado ${ }^{23}$.

Volviendo a Mann y su interesante teoría del Moisés egipcio, que nos ha llevado a tomar estas notas, su idea nos parece discutible. Creemos que los avanzados conceptos higiénicos de Moisés no provenían de su etnia, sino de la educación recibida como príncipe de Egipto. $\mathrm{O}$, anteponiendo la fe a la ciencia, de Dios.

\section{Resumen}

Leyendo una vez más los Evangelios, encontramos una discusión de Jesús con los fariseos sobre el lavado de manos antes de comer, que sus discípulos no respetaban. Como Jesús pareciera minimizar la utilidad de esta regla de oro para la medicina actual, fuimos a buscar otras notas bíblicas sobre las disposiciones higiénicas de aquellos tiempos, siguiendo una revisión que hiciera Thomas Mann para una de sus obras menores. Aparecen, fundamentalmente en el Levítico, numerosas recomendaciones, disposiciones y reglas que Moisés, invocando la autoridad de Yahvé, entregó al pueblo que salía de Egipto en pos de la Tierra Prometida, comprendiendo eliminación de excretas, alimentos recomendables y no recomendables, y aislamiento de enfermos en el caso de enfermedades que consideraban contagiosas, como lepra y gonorrea. También se detallaban en ellas la descontaminación de ropas y de casas, al igual que de otros objetos que habían estado en contacto con elementos estimados impuros, como cadáveres. Algunas de estas disposiciones, entre ellas las relativas al aislamiento de los enfermos, hoy nos parecen adelantadas a su época.

\section{Referencias bibliográficas}

1.- Mateo 15:1-19. Nuevo Testamento. Sociedad de San Pablo, Lima 2008 .

2.- Marcos 7: 1- 23. Nuevo Testamento. Sociedad de San Pablo, Lima 2008

3.- Mann, T. Las tablas de la ley. En: La muerte en Venecia. 7a. edición. Editorial Planeta, Barcelona 1977; pp: 89-157.

4.- Deuteronomio 23: 9,14. La Sagrada Biblia. Edición ecuménica. Versión directa de los textos primitivos por Mons. Dr. Juan Straubinger. La Prensa Católica, Chicago-México 1958.

5.- Levítico 15:1- 33. Ibid.

6.- Levítico 11: 1-20. Ibid.

7.- La Biblia Vulgata Latina, traducida en español y anotada conforme al sentido de los santos Padres y expositores católicos, por el Padre Phelipe Scio. de San Miguel, de las escuelas pías. Dedicado al Príncipe de Asturias, nuestro señor. Segunda edición, revista, correjida y aumentada por el mismo traductor. Tomo II del Antiguo Testamento. El Éxodo y el Levítico. Madrid, en la imprenta de Benito Cano, MDCCXCV.

8.- Levítico 7 : 23-26. La Sagrada Biblia. Edición ecuménica. Versión directa de los textos primitivos por Mons. Dr. Juan Straubinger. La Prensa Católica, Chicago-México 1958.

9.- Levítico 11: 24-39. Ibid.

10.- Job 2:7. Ibid.

11.- Ledermann W. Staphylococcus aureus, el patógeno persistente. En: Una historia personal de las bacterias. RIL editores, Santiago 2007; 19-33.

12.- Verghese A, Gallemore G. Kernig's and Brudzinski's signs revisited. Rev Infect Dis 1987; 9 (6): 1187-92.

13.- Alexander Gilchrist. Life and works of William Blake London 1880.

14.- Bentley Jr GE. The stranger from paradise. A biography of William Blake. Yale University Press 2001.

15.- Filippini F. La enfermedad de Job. Medicina \& Cultura Feb 2008; 2 (13): 2.

16.- Eclesiástico 38: 1-15. La Sagrada Biblia. Edición ecuménica. Versión directa de los textos primitivos por Mons. Dr. Juan Straubinger. La Prensa Católica, Chicago-México 1958.

17.- Números $25: 1-9$. Ibid.

18.- Levítico 13: 38-44.Ibid.

19.- Levítico 13:45-46.Ibid.

20.- Números $5: 1-2$. Ibid.

21.- Números 12:10. Ibid.

22.- Levítico 13: 47-59.Ibid.

23.- Levítico 14:33- 54.Ibid. 